\title{
Desempenho e saúde de bezerras alimentadas com leite sem resíduo de drogas antimicrobianas ou leite de vacas tratadas contra mastite adicionado ou não de probiótico
}

\author{
[Performance and health of calves fed milk without antimicrobials residue or milk from \\ mastitis treated cows with or without probiotic] \\ C.G. Batista ${ }^{1}$, S.G. Coelho ${ }^{2 *}$, E. Rabelo ${ }^{3}$, A.M.Q. Lana ${ }^{2}$, A.U. Carvalho ${ }^{2}$, \\ R.B. Reis $^{2}$, H.M. Saturnino ${ }^{2}$ \\ ${ }^{1}$ Aluna de pós-graduação - EV-UFMG - Belo Horizonte, MG \\ ${ }^{2}$ Escola de Veterinária-Universidade Federal de Minas Gerais \\ Caixa Postal 567 \\ 30123-970 - Belo Horizonte, MG \\ ${ }^{3}$ Rehagro - Belo Horizonte, MG
}

\begin{abstract}
RESUMO
Quarenta e oito bezerras da raça Holandesa, de um a 60 dias de idade, foram utilizadas para avaliar os efeitos da adição ou não de Lactobacillus acidophillus, Bifidobacterium bifidum e Enterococus faecium ao leite sem resíduo de antimicrobiano (L) e ao leite de vacas em tratamento de mastite (LTM), sobre o consumo de alimentos, ganho de peso e incidência e duração de diarréia. $\mathrm{O}$ consumo de concentrado e água foi medido diariamente, e o ganho de peso semanalmente. Utilizou-se um delineamento inteiramente ao acaso, em esquema de parcelas subdivididas, com 12 repetições. Os tratamentos consistiram de um arranjo fatorial $2 \times 2$ (L ou LTM e ausência ou presença de probiótico). A adição de probiótico reduziu o número de dias com diarréia no grupo de animais que recebeu leite sem resíduo de antimicrobiano $(\mathrm{P}<0,05)$, mas não houve efeito sobre os animais que receberam leite de vacas em tratamento de mastite. Também não houve efeito do probiótico sobre os consumos de concentrado e de água, e sobre o ganho de peso e a incidência de diarréia.
\end{abstract}

Palavras-chave: bezerra, desempenho, leite, antimicrobiano, probiótico

\begin{abstract}
Forty-eight Holstein calves from birth until 60-day-old were used to evaluate the effect of commercial probiotic Biobac ${ }^{\circledR}$ (Lactobacillus acidophillus, Bifidobacterium bifidum, and Enterococcus faecium) in addition to milk without antimicrobials residue or milk from mastitis treatead cows on theoccurrence and the length of diarrhea. Consumption of concentrate and water were daily measured and the weight was weekly measured. The experiment was carried out according to a random sample design with 12 repetitions for each treatment, arranged in a split plot. The plots were composed by four treatments combined in a factorial arrangement of 2x2. Subplots were composed by the evaluation times. The addition of probiotic was beneficial to reduce the diarrhea period in the calves fed milk without antimicrobial residue. The consumption of concentrate, water, and the weights of the calves were not different among the groups, irrespectively of probiotic supply.
\end{abstract}

Keywords: dairy calf, antimicrobials, development, milk, probiotic

Recebido em 25 de abril de 2007

Aceito em 31 de janeiro de 2008

*Autor para correspondência (corresponding author)

E-mail: sandra@vet.ufmg.br

Apoio: FAPEMIG 


\section{INTRODUÇÃO}

O manejo adequado dos animais jovens merece destaque por sua grande importância econômica. A fase de aleitamento é, provavelmente, a mais crítica, exigindo que parte do leite produzido seja desviado para a alimentação dos bezerros. Esta também é a fase em que os bezerros são mais acometidos por doenças, sendo a diarréia um dos maiores problemas nas duas primeiras semanas de vida e as doenças respiratórias, o maior problema após as quatro semanas de vida (Nabuurs et al., 2001; Buzinaro et al., 2003).

Vários fatores contribuem para a alta incidência de doenças intestinais e respiratórias na fase inicial de criação de bezerros. Ao nascerem, geralmente os bezerros são separados de suas mães, dificultando a aquisição de uma flora protetora advinda da mãe. Aliado a isso, consomem quantidades restritas de colostro e leite, o que pode comprometer as defesas imunológicas e deprimir a flora intestinal. São ainda submetidos a estresse, como o de transporte, mudanças alimentares e criação em bezerreiros que muitas vezes não oferecem boas condições sanitárias, provocando a constante exposição a agentes patogênicos (Timmerman et al., 2005).

Para Fuller (1997), o estabelecimento e a manutenção de microrganismos benéficos no intestino dos animais podem ajudar a suprimir os microrganismos patogênicos, reduzindo ou eliminando as diarréias. Dessa forma, os probióticos aparecem como ferramenta alternativa na prevenção e no tratamento das diarréias.

Abe et al. (1995) estudaram o desempenho de bezerros suplementados com probióticos administrados via sucedâneo do leite (Bifidobacterium pseudolongum, B. thermophilus, Enterococcus faecium $e$ Lactobacillus acidophilus). A utilização de probióticos melhorou o ganho de peso corporal total, $31,4 \mathrm{~kg}$ e $25,4 \mathrm{~kg}$, e a conversão alimentar, $2,08 \mathrm{~kg}$ e $2,37 \mathrm{~kg}$, observados nos grupos experimental e controle, respectivamente.

Meyer (2000), ao avaliar o efeito da adição de $L$. acidophillus e E. faecium e Saccharomyces cerevisiae ao leite integral e ao sucedâneo, concluiu que a adição de probiótico é benéfica para bezerros aleitados com sucedâneo a partir do terceiro dia de idade, pela melhora no ganho de peso e na conversão alimentar até o desaleitamento.

Timmerman et al. (2005) utilizaram probióticos multiespécie - microrganismos isolados do trato gastrintestinal humano e do trato gastrintestinal de bezerros - para avaliar o crescimento e a saúde dos animais. Os autores não encontraram diferenças entre os dois probióticos, no entanto observaram diminuição na incidência e duração (dias) da diarréia e na porcentagem de animais que necessitaram de tratamento terapêutico.

O objetivo deste trabalho foi avaliar os efeitos de um probiótico comercial, constituído de $L$. acidophillus, B. bifidum e E. faecium, sobre a saúde e o desempenho de bezerras durante o período de aleitamento, em uma fazenda comercial com grande número de bezerras alojadas em bezerreiros individuais e submetidas a grande desafio devido à alta densidade populacional.

\section{MATERIAL E MÉTODOS}

O experimento, realizado em uma propriedade leiteira comercial no período de fevereiro a maio de 2004, utilizou 48 bezerras da raça Holandesa, distribuídas em quatro grupos experimentais, com 12 repetições por grupo.

Todas as bezerras, separadas de suas mães imediatamente após o nascimento, receberam quatro litros de colostro, proveniente de um banco de colostro, no máximo duas horas pósnascimento. Todo colostro fornecido possuía concentração de imunoglobulinas acima de $50 \mathrm{mg} / \mathrm{ml}$.

Os grupos experimentais foram assim definidos: no grupo L, os animais receberam quatro litros de leite sem resíduo de antimicrobiano; no grupo $\mathrm{LP}$, receberam quatro litros de leite sem resíduo de antimicrobiano mais $2 \mathrm{~g} / \mathrm{dia}$ probiótico Biobac $^{\circledR 1}$ (L. acidophillus: $3,33 \times 10^{6} \mathrm{UFC} / \mathrm{g} ; B$. bifidum: $3,33 \times 10^{6} \mathrm{UFC} / \mathrm{g} ;$ E. faecium; $3,33 \times 10^{6}$ UFC/g); no grupo LTM, receberam quatro litros de leite de vacas em tratamento de mastite; e no grupo LTMP, receberam quatro litros de leite de vacas em tratamento de mastite mais $2 \mathrm{~g} / \mathrm{dia}$

${ }^{1}$ Biobac $^{\circledR}$ : Laboratório CHR Hansen - Valinhos, SP - Brasil. 
probiótico Biobac ${ }^{\circledR 1}$. Os animais do grupo LP e LTMP receberam também $4 \mathrm{~g}$ de probiótico Biobac $^{\circledR 1}$ em gel antes do fornecimento do colostro.

As bezerras foram alojadas individualmente, durante todo o período de aleitamento até os 60 dias de idade, em casinhas de metal mantidas sobre cama de areia. $\mathrm{O}$ concentrado oferecido à vontade a partir do terceiro dia de idade, formulado na própria fazenda, apresentava a seguinte composição: $80,2 \%$ de matéria seca, $23,6 \%$ de proteína bruta, $17,0 \%$ de FDN, $87,7 \%$ de NDT, $3,2 \%$ de extrato etéreo, $6,3 \%$ de minerais, $0,1 \%$ de cálcio e $0,6 \%$ de fósforo. A água foi fornecida à vontade, e o consumo voluntário diário de concentrado e água foi determinado calculando-se a diferença entre o fornecido e as sobras.

Nas amostras pré-secas dos alimentos, determinaram-se a matéria seca, em estufa a $105^{\circ} \mathrm{C}$, a proteína bruta, pelo método de Kjeldhal, os componentes da parede celular, pelo método seqüencial de Van Soest et al. (1991), o cálcio e o fósforo, segundo AOAC (Official...,1980).

Os animais foram pesados 24 horas após o nascimento e a cada sete dias antes do fornecimento de alimentos. Diariamente, após o aleitamento, todas as bezerras foram observadas quanto às condições físicas, mensurando-se a temperatura retal e observando-se a presença de sinais de enfermidades.

Todos os dados referentes às diarréias foram anotados seguindo a metodologia citada por Ferreira (2001): idade de aparecimento da diarréia e severidade do quadro de acordo com o grau de desidratação do animal, tempo de recuperação e mudanças no comportamento, avaliadas pelo grau de depressão clínica que variou de 0 a 3 sendo 0 - animal normal; 1 animal apático, mas se alimentando; 2- animal apático sem se alimentar; 3- animal em decúbito. Foi avaliada, diariamente, a consistência das fezes utilizando-se o seguinte escore: 0- normal; 1- anormal, tendendo à consistência pastosa, mas sem diarréia; 2- pastosa com diarréia moderada; 3- pastosa a líquida ou mesmo líquida, com diarréia severa.
Para detecção dos agentes causadores de diarréia, foram colhidas amostras de fezes, aproximadamente $30 \mathrm{~g}$, por meio de massagem na ampola retal, nos dois primeiros dias do curso da diarréia. As amostras foram acondicionadas em embalagens plásticas e congeladas a $-20^{\circ} \mathrm{C}$. Posteriormente, foram descongeladas e processadas segundo as técnicas descritas no manual do kit Elisa Bio-X digestive.

As dietas líquida e sólida foram mantidas durante o curso da diarréia. O tratamento da diarréia consistiu no uso imediato de soro oral constituído por $20 \mathrm{~g}$ de glicose de milho, $5 \mathrm{~g}$ de cloreto de sódio, $4 \mathrm{~g}$ de bicarbonato de sódio e $1 \mathrm{~g}$ de cloreto de potássio diluídos em 1 litro de água, fornecido aos primeiros sinais de diarréia, bem como na administração de drogas antimicrobianas quando a temperatura corporal estava elevada.

O experimento foi realizado em delineamento inteiramente ao acaso, com 12 repetições por tratamento, em arranjo em parcelas subdivididas. A parcela foi composta por quatro tratamentos constituídos de arranjo fatorial $2 \times 2$, sendo dois tipos de leite (L e LTM) e adição ou não de probiótico. A subparcela foi composta pelas nove semanas de avaliação. As análises foram realizadas utilizando-se o SAEG (Sistema...,2000). Para testar as diferenças entre as médias dos tratamentos, utilizou-se o teste SNK $(\mathrm{P}<0,05)$. Para os tempos de avaliação, fez-se ajuste de modelos de regressão.

\section{RESULTADOS E DISCUSSÃO}

Todas as bezerras apresentaram quadro de diarréia iniciado entre o sétimo e $11^{\circ}$ dia de vida. Estes resultados diferem dos encontrados por Selim e Culler (1997) e Wray (1990), ao afirmarem que leite de vacas em tratamento contra mastite e com resíduos de antimicrobianos contribui para o aumento da incidência de diarréia em bezerros. Neste trabalho, todos os animais apresentaram quadro de diarréia independentemente da qualidade do leite.

Dois animais do grupo L apresentaram quadro de depressão nível 2 - animal apático, com alteração do consumo de leite. Seis bezerras, com temperatura elevada, foram tratadas com antimicrobianos, e destas, três pertenciam ao grupo L, duas ao LTM e uma ao LP. 
$\mathrm{Na}$ Tab. 1 observam-se os patógenos identificados nas amostras de fezes colhidas nos diferentes grupos. Foram processadas 22 amostras, sendo seis amostras dos grupos L e LP e cinco amostras dos grupos LTM e LTMP. Em 15 amostras foi encontrado Cryptosporidium parvum, em duas destas Rotavírus e em uma Coronavirus. Em quatro amostras verificou-se apenas Rotavírus, em uma outra Rotavírus e Coronavirus e em duas não foi identificado nenhum patógeno.

Tabela 1. Agentes causadores de diarréia identificados nas fezes de bezerras segundo os tratamentos (grupos)

\begin{tabular}{lccccc}
\hline Agente & Grupo L & Grupo LP & Grupo LTM & Grupo LTMP & Total \\
\hline Cryptosporidium & 1 & 4 & 6 & 4 & 15 \\
Rotavírus & 3 & 1 & 1 & 2 & 7 \\
Coronavírus & 1 & & 1 & & 2 \\
\hline
\end{tabular}

L: leite sem resíduo antimicrobiano; LP: leite sem resíduo antimicrobiano adicionado de probiótico Biobac ${ }^{1}$; LTM: leite de vacas em tratamento de mastite; LTMP: leite de vacas em tratamento de mastite adicionado de probiótico.

Todos os agentes diagnosticados nas amostras causam danos aos microvilos intestinais, o que predispõe à combinação de patógenos. Rebhun (2000) mencionou que as combinações de patógenos intestinais, nos neonatos, complicam o tratamento e pioram os sinais clínicos e o prognóstico. Mais ainda, tendem a elevar a mortalidade e predispõem à má nutrição, em razão da má digestão e absorção que persistem por uma semana ou mais, sendo a desidratação a principal causa de morte nos quadros de diarréia. Neste estudo, não ocorreram mortes. A imediata hidratação dos animais com soro oral, a manutenção da dieta líquida e o tratamento com antimicrobianos quando a temperatura corporal se elevou contribuíram para a não ocorrência de óbitos.

A incidência de Cryptosporidium foi mais alta nas bezerras do grupo LTM: 10 casos em 12 amostras. As do grupo L apresentaram cinco casos em 11 amostras. Sabe-se que criptosporidiose acomete bezerros imunocomprometidos (Rebhun, 2000). O leite de vacas em tratamento de mastite pode resultar em bactérias patogênicas mais resistentes e na diminuição da flora protetora, levando à diminuição das respostas imunológicas e, talvez, ao maior número de casos de criptosporidiose.

A duração da diarréia nos diferentes grupos pode ser observada na Tab.2. O maior tempo $(\mathrm{P}<0,05)$ foi observado no grupo L, seguido pelos grupos LP e LTMP, no entanto esses não foram diferentes entre si $(\mathrm{P}>0,05)$. A menor duração do período de diarréia no grupo LTM talvez possa ser atribuída à ação de compostos de antimicrobianos metabolicamente ativos no leite fornecido às bezerras, o que reduziu as infecções secundárias que poderiam agravar os quadros de diarréia.

Tabela 2. Dias com diarréia em bezerras segundo os tratamentos

\begin{tabular}{ccc} 
Probiótico & $\begin{array}{c}\text { Leite sem } \\
\text { resíduo } \\
\text { antimicrobiano }\end{array}$ & $\begin{array}{c}\text { Leite de vacas } \\
\text { em tratamento } \\
\text { de mastite }\end{array}$ \\
\hline Sem & $10,5 \mathrm{Ab}$ & $5,7 \mathrm{Ba}$ \\
Com & $7,7 \mathrm{Aa}$ & $7,3 \mathrm{Aa}$
\end{tabular}

Médias seguidas de letras distintas maiúsculas na linha e letras minúsculas na coluna diferem entre si pelo teste SNK $(\mathrm{P}<0,05)$.

Houve diferença entre os grupos L e LP $(\mathrm{P}<0,05)$ quanto à duração da diarréia, mostrando eficiência do probiótico em reduzir os dias em diarréia. Dados semelhantes foram mencionados por Gibson et al. (1997) que, ao revisaram a literatura sobre os efeitos da utilização de probióticos para animais com diarréia e enterite, verificaram que em 71,5\% dos animais houve efeito positivo em erradicar ou amenizar o quadro de diarréia. Os mecanismos apontados como causadores desses efeitos foram a inibição da proliferação de bactérias patogênicas pela produção de ácidos orgânicos, a redução do $\mathrm{pH}$ e a produção de substâncias antibióticas; o antagonismo competitivo entre os microrganismos do probiótico e os patógenos; e a estimulação do sistema imune dos bezerros.

Não houve diferença entre os grupos LTMP, LTM e LP, $(\mathrm{P}>0,05)$, o que sugere que o fornecimento de probiótico na presença de antibiótico não foi eficiente.

O consumo de matéria seca do concentrado pode ser observado na Tab. 3. Não houve diferença no consumo semanal de concentrado na matéria 
seca entre grupos nas seis semanas iniciais. $\mathrm{Na}$ sétima e oitava semanas, não houve diferença $(\mathrm{P}>0,05)$ entre os grupos L, LTM e LP, mas os animais do grupo LTMP consumiram menos em relação aos animais dos grupos L e LP. No final da sétima e na oitava semana, as bezerras foram acometidas por pneumonia, sendo maior o número de bezerras doentes nos grupos LTM e LTMP, o que resultou em menor consumo nas bezerras do grupo LTMP. Na nona semana, o consumo semanal de concentrado foi novamente semelhante $(\mathrm{P}>0,05)$ entre os grupos, indicando recuperação dos animais.

Todos os grupos seguiram o modelo de regressão quadrático, com alta explicação de dados $\left(\mathrm{R}^{2}\right)$ variando de 98,3\% a 99,4\% (Tab.4). Todos os grupos apresentaram curvas de consumo que se elevaram acentuadamente a partir da primeira semana de vida.

Tabela 3. Consumo médio diário de matéria seca do concentrado $(\mathrm{g})$ por bezerras segundo os tratamentos e as semanas

\begin{tabular}{ccccc}
\hline Semana & Grupo L & $\begin{array}{c}\text { Grupo LTM } \\
\text { Consumo g/dia }\end{array}$ & $\begin{array}{c}\text { Grupo LP } \\
\text { Grupo LTMP }\end{array}$ \\
\hline 1 & $29,0 \mathrm{~A}$ & $28,2 \mathrm{~A}$ & $30,8 \mathrm{~A}$ & $37,6 \mathrm{~A}$ \\
2 & $42,0 \mathrm{~A}$ & $33,0 \mathrm{~A}$ & $58,5 \mathrm{~A}$ & $67,4 \mathrm{~A}$ \\
3 & $212,6 \mathrm{~A}$ & $271,2 \mathrm{~A}$ & $257,7 \mathrm{~A}$ & $213,8 \mathrm{~A}$ \\
5 & $396,3 \mathrm{~A}$ & $340,8 \mathrm{~A}$ & $458,1 \mathrm{~A}$ & $350,7 \mathrm{~A}$ \\
6 & $649,6 \mathrm{~A}$ & $606,9 \mathrm{~A}$ & $625,0 \mathrm{~A}$ & $546,4 \mathrm{~A}$ \\
7 & $903,3 \mathrm{~A}$ & $772,0 \mathrm{~A}$ & $839,12 \mathrm{~A}$ & $708,4 \mathrm{~A}$ \\
8 & $1204,9 \mathrm{~A}$ & $936,5 \mathrm{~A}$ & $1218,2 \mathrm{~A}$ & $883,6 \mathrm{~B}$ \\
9 & $1378,2 \mathrm{~A}$ & $1161,6 \mathrm{AB}$ & $1376,6 \mathrm{~A}$ & $966,2 \mathrm{~B}$ \\
& $1540,9 \mathrm{~A}$ & $1376,5 \mathrm{~A}$ & $1581,2 \mathrm{~A}$ & $1287,7 \mathrm{~A}$ \\
\hline
\end{tabular}

Médias seguidas de letras distintas na linha diferem entre si pelo teste $\mathrm{SNK}(\mathrm{P}<0,05)$.

L: leite sem resíduo antimicrobiano; LP: leite sem resíduo antimicrobiano adicionado de probiótico Biobac ${ }^{1}$; LTM: leite de vacas em tratamento de mastite; LTMP: leite de vacas em tratamento de mastite adicionado de probiótico.

CV na $7^{\mathrm{a}}$ semana 25,8 ; e o na $8^{\mathrm{a}}$ semana, $21,7 \%$.

Tabela 4. Equações de regressão do consumo do concentrado (MS) de bezerras segundo os tratamentos

\begin{tabular}{lll} 
Resposta & Equação & $\mathrm{R}^{2}(\%)$ \\
\hline Consumo de concentrado L & $39,27-1,74^{* *} \operatorname{dias}+0,458^{* *} \operatorname{dias}^{2}$ & 98,27 \\
Consumo de concentrado LTM & $-6,47+1,08^{* *} \operatorname{dias}+0,4362^{* *} \operatorname{dias}^{2}$ & 99,27 \\
Consumo de concentrado L P & $-7,78+4,58^{* *} \operatorname{dias}+0,35^{* *} \operatorname{dias}^{2}$ & 98,80 \\
Consumo de concentrado LTMP & $44,90-7,33^{* *} \operatorname{dias}+0,49^{* *} \operatorname{dias}^{2}$ & 99,40 \\
\hline
\end{tabular}

** $(\mathrm{P}<0,01)$

L: leite sem resíduo antimicrobiano; LP: leite sem resíduo antimicrobiano adicionado de probiótico Biobac; LTM: leite de vacas em tratamento de mastite; LTMP: leite de vacas em tratamento de mastite adicionado de probiótico.

$\mathrm{Na}$ Tab. 5 pode ser observado o consumo de água. Não foram observadas diferenças de consumo entre os grupos $(\mathrm{P}>0,05)$, dessa forma, os dados foram agrupados. Observaram-se diferenças apenas entre as semanas avaliadas $(\mathrm{P}<0,05)$.

Na primeira semana de vida, o consumo de água foi maior que nas semanas $3,4,5,6,7$ e 8 . Todos os animais iniciaram ou terminaram os quadros de diarréia no final da primeira e início da segunda semana. A desidratação causada pela diarréia pode ter causado maior consumo de água na primeira semana.
Tabela 5. Consumo médio diário de água por semana nos quatro grupos experimentais

\begin{tabular}{cc}
\hline Semana & $\begin{array}{c}\text { Consumo médio de } \\
\text { água }(1)\end{array}$ \\
\hline 1 & $5,31 \mathrm{~B}$ \\
2 & $4,896 \mathrm{BC}$ \\
3 & $4,719 \mathrm{CD}$ \\
4 & $4,588 \mathrm{CD}$ \\
5 & $4,302 \mathrm{CD}$ \\
6 & $4,110 \mathrm{D}$ \\
7 & $4,037 \mathrm{D}$ \\
8 & $4,693 \mathrm{CD}$ \\
9 & $6,145 \mathrm{~A}$ \\
\hline
\end{tabular}

Médias seguidas de letras distintas na coluna diferem entre si pelo teste SNK $(\mathrm{P}<0,05)$. 
Na Tab. 6 são apresentados os dados de peso das bezerras nas semanas avaliadas. Não foram observadas diferenças de peso entre os grupos $(\mathrm{P}>0,05)$, dessa forma, os dados foram agrupados. Observaram-se diferenças apenas entre as semanas avaliadas $(\mathrm{P}<0,05)$.

Tabela 6. Médias de pesos $(\mathrm{kg})$ por idade das bezerras

\begin{tabular}{cc}
\hline Idade em dias & Média de pesos $(\mathrm{kg})$ \\
\hline 2 & $38,8 \mathrm{H}$ \\
7 & $40,0 \mathrm{H}$ \\
14 & $42,8 \mathrm{G}$ \\
21 & $43,9 \mathrm{G}$ \\
28 & $47,0 \mathrm{~F}$ \\
35 & $51,7 \mathrm{E}$ \\
42 & $58,0 \mathrm{D}$ \\
49 & $64,2 \mathrm{C}$ \\
56 & $69,8 \mathrm{~B}$ \\
60 & $73,7 \mathrm{~A}$ \\
\hline
\end{tabular}

Médias seguidas de letras distintas diferem entre si pelo teste SNK $(\mathrm{P}<0,05)$.

$\mathrm{Na}$ Tab. 7 são apresentadas as equações de regressão para ganho de peso. Todos os grupos seguem o modelo quadrático com alto grau de explicação, de 99,2 a 99,7\%. As equações de regressão demonstram início de ganho de peso a partir da primeira semana de vida.

Gibson et al. (1997) relataram que a utilização de probiótico pode alterar a ingestão de alimento e o ganho de peso, melhorar a digestão da lactose e a motilidade do trato gastrintestinal, estimular as defesas imunológicas e, conseqüentemente, melhorar o desempenho e a saúde dos bezerros. Como os resultados deste experimento não indicaram diferença entre os grupos experimentais no consumo e no ganho de peso, o beneficio do uso do probiótico não se confirmou para essas características.

Apesar de terem ocorrido diarréias severas, com fezes tendendo a líquidas ou mesmo líquidas, apenas 4,2\% das bezerras apresentaram-se deprimidas, e só em $14,5 \%$ foi necessário o uso de antimicrobiano para controle da diarréia, fato que pode justificar o consumo e o ganho de peso semelhantes entre os grupos, independente da redução na duração da diarréia.

Tabela 7. Equações de regressão dos pesos $(\mathrm{kg})$ dos diferentes grupos experimentais

\begin{tabular}{lll}
\hline Resposta & Equação & $\mathrm{R}^{2}(\%)$ \\
\hline Pesos das bezerras L & $38,55-0,04^{* *} \operatorname{dias}+0,01^{* *} \operatorname{dias}^{2}$ & 99,75 \\
Pesos das bezerras LTM & $38,92+0,04^{* *} \operatorname{dias}+0,0096^{* *} \operatorname{dias}^{2}$ & 99,75 \\
Pesos das bezerras LP & $39,65+0,036^{* *} \operatorname{dias}+0,0092^{* *} \operatorname{dias}^{2}$ & 99,20 \\
Pesos das bezerras LTMP & $39,00+0,019^{* *} \operatorname{dias}+0,068^{* *} \operatorname{dias}^{2}$ & 99,27 \\
\hline
\end{tabular}
** $(\mathrm{P}<0,01)$.

L: leite sem resíduo antimicrobiano; LP: leite sem resíduo antimicrobiano adicionado de probiótico Biobac; LTM: leite de vacas em tratamento de mastite; LTMP: leite de vacas em tratamento de mastite adicionado de probiótico.

\section{CONCLUSÕES}

A adição de probiótico ao leite sem resíduo de antibiótico é uma alternativa para reduzir os dias em diarréia em bezerras, sem influenciar o consumo e o ganho de peso dos animais. O fornecimento de leite de vacas em tratamento de mastite, isto é, com resíduo de drogas antimicrobianas para bezerras deve ser melhor estudado, avaliando-se seu impacto no desenvolvimento da bezerra ao longo do tempo e os efeitos no surgimento de resistência bacteriana e/ou reações adversas.

\section{AGRADECIMENTOS}

Os autores agradecem à Fazenda São João, por permitir realizar este experimento em suas instalações e à CHR-Hansen, pelo apoio para realização deste trabalho.

\section{REFERÊNCIAS BIBLIOGRÁFICAS}

ABE., F; ISHIBASHI; N.; SHIMAMURA, S. Effect of administration of bifidobateria and lactic acid bacteria to newborn calves and piglets. J. Dairy Sci., v.78, p.2838-2846, 1995. 
BUZINARO, M.G.; MISTIERI, M.L.A.; CARVALHO, A.A.B. et al. Prevalência de rotavírus do grupo A em fezes diarréicas de bezerros de corte em sistema semi-intensivo de produção. Arq. Bras. Med. Vet. Zootec., v.55, p.266-270, 2003.

FERREIRA, F. Fluidoterapia endovenosa e oral em bezerros com diarréia osmótica induzida. 2001. 74f. Dissertação (Mestrado) - Escola de Veterinária, Universidade Federal de Minas Gerais, Belo Horizonte, MG.

FULLER, R. (Ed). Probiotics 2: applications and practical aspects. London: Chapman \& Hall, 1997. $212 p$

GIBSON, G.R.; SAAVEDRA, J.M.; MacFARLANE, S. et al. Probiotic and intestinal infections. In: FULLER, R. (Ed). Probiotics 2: applications and practical aspects. London: Chapman \& Hall, 1997. cap.2, p.10-39.

MEYER, P.M. Efeito da adição de lactobacillos acidóphilus, Enterococcus faecium $e$ Saccharomyces cerevisial ao leito integral ou sucedâneo no desempenho de bezerros (as) da Raça Holandesa durante e após o aleitamento. 2000. 86f. Dissertação (Mestrado) - Escola Superior de Agricultura "Luiz de Queiroz", Universidade de São Paulo, Piracicaba, SP.
NABUURS, M.J.; ESSEN,G.J.; NABUURS,P. et al. Thirty minutes transport causes small intestinal acidosis in pigs. Res. Vet. Sci., v.70, p.123-127, 2001.

OFFICIAL methods of analysis. 13. ed. Washington, DC: AOAC, 1980. 1015p.

REBHUN,W.C. (Ed). Doenças do gado leiteiro. São Paulo: Rocca, 2000. 654p.

SELIM, S.A.; CULLOR, J.S. Number of viable bacteria and presumptive antibiotic residues in milk fed to calves on commercial dairies. $J$. Animal Sci., v.211, p.1029-1034, 1997.

SISTEMAS de análises estatísticas e genéticasSAEG. Versão 7.0. Viçosa: UFV, 1998 (Versão 7.0).

TIMMERMAN, H.M.; MULDER, L.; EVERST, $H$. et al. Health and grow of veal calves fed milk replacers with or without probiotics. J. Anim. Sci., v.88, p.2154-2165, 2005.

VAN SOEST, P.J. (Ed). Nutritional ecology of the ruminant. 2.ed. London: Cornell University, 1991. 476p.

WRAY, C.; FURNISS, S.; BENHAM, CH. Feed antibiotic - contaminated waste milk to calves effects on physical performance and antibiotic sensivity of gut flora. Br. Vet. J., v.146, p.80-87, 1990. 